\title{
Early Evolution of the Vertebrate Eye-Fossil Evidence
}

\author{
Gavin C. Young
}

Published online: 18 October 2008

(C) Springer Science + Business Media, LLC 2008

\begin{abstract}
Evidence of detailed brain morphology is illustrated and described for 400-million-year-old fossil skulls and braincases of early vertebrates (placoderm fishes). Their significance is summarized in the context of the historical development of knowledge of vertebrate anatomy, both before and since the time of Charles Darwin. These ancient extinct fishes show a unique type of preservation of the cartilaginous braincase and demonstrate a combination of characters unknown in other vertebrate species, living or extinct. The structure of the oldest detailed fossil evidence for the vertebrate eye and brain indicates a legacy from an ancestral segmented animal, in which the braincase is still partly subdivided, and the arrangement of nerves and muscles controlling eye movement was intermediate between the living jawless and jawed vertebrate groups. With their unique structure, these placoderms fill a gap in vertebrate morphology and also in the vertebrate fossil record. Like many other vertebrate fossils elucidated since Darwin's time, they are key examples of the transitional forms that he predicted, showing combinations of characters that have never been observed together in living species.
\end{abstract}

Keywords Fossils · Vertebrates · Brain structure · Cranial nerves - Eye evolution · Transitional forms . Charles Darwin $\cdot$ Intelligent design

G. C. Young $(\bowtie)$

Research School of Earth Sciences,

The Australian National University,

Canberra, Australia

e-mail: Gavin.Young@anu.edu.au

\section{Introduction}

The vertebrate eye has been presented time and again as a key example of biological complexity that evolution cannot explain. Proponents of "Intelligent Design" use the eye as an example of "irreducible complexity" and claim to challenge Darwinian evolution with such questions as, "could the human eye be the result of chance"? The same issue, raised by the theologian William Paley in his 1802 book, Natural Theology, was confronted in 1859 by Charles Darwin in The Origin of Species by Means of Natural Selection. Paley noted that the more spherical lens of a fish eye compared to that of a land vertebrate showed each was adapted to the refractive index of the water or air in which the animal lived. "What plainer evidence than design could there be?" he asked.

Darwin's response (1859, p. 133) has been widely quoted: "To suppose that the eye with all its inimitable contrivances...could have been formed by natural selection, seems, I freely confess, absurd in the highest degree." Darwin was considering the eye of vertebrate animals generally. Modern supporters of "Intelligent Design," not necessarily well grounded in comparative anatomy, may believe that the human eye is somehow more perfect than eyes of other vertebrates - but mammals, birds, reptiles, amphibians and fishes all have eyes of similar complexity, as do many "invertebrates" (although on a different structural plan), such as cephalopods (living) and trilobites (extinct).

Darwin recognized that the theory that life had evolved over a vast time also had implications for the fossil record as then known. He devoted one chapter in The Origin of Species to "Imperfection of the Geological Record" and another to the "Geological Succession of Organic Beings". His problem was the distinctness of living species, used as a major argument against the idea that species could change. If one 
species could evolve into another, why were they not "blended together by innumerable transitional links" (Darwin 1859 , p. 234)? His proposed solution was a "process of extermination" due to natural selection, that removed an "enormous number" of pre-existing "intermediate varieties." Why, then, were such transitional forms not readily found in "every geological formation and...stratum"? His explanation was "the extreme imperfection of the geological record."

Regarding "organs of extreme perfection and complication," Darwin (1859, p. 133) noted that "gradations through which an organ has been perfected" should be found among the "lineal progenitors" of the species in question, but this is "scarcely possible" (they are all extinct). To understand how a complex organ may have evolved, it was necessary to look at "other species and genera of the same group... collateral descendants from the same parent-form...to see what gradations are possible." Put another way, because fossilization of such organs was almost inconceivable, the best one could do was examine the corresponding organ in related living species.

The information summarized here is relevant to all of these issues. I describe and illustrate some remarkable fossil preservation concerning the eye and brain of early vertebrates-animals that lived more than 400-million-years-ago (mya), showing details that Charles Darwin could not have imagined possible. To place the understanding of such fossils in context, it is necessary first to briefly summarize the development of knowledge of the vertebrate eye in living species (for explanation of terms in boldface see Glossary of Terms).

\section{Eyes of Living Vertebrates}

In 1859, Darwin already could benefit from the efforts of thousands of scientists going back some two millennia. Building on investigations of the Greek physician Herophilus (335-280 BC), the eye muscles of vertebrates were first documented in the Myology treatise of Claudius Galen of Pergamum (130-200 AD), who dissected and named the tunics of the eye, and introduced terms like "retina" and "cornea". Galen was also the first to describe the cranial nerves correctly (seven of the 12 of modern anatomy) and demonstrated that nerves originated from the brain and spinal cord, thereby overturning the authority of Aristotle (384-322 BC), who believed that nerves originated in the heart. Studying in Montpellier, the French anatomist Rondelet (1507-1566) first found the cartilaginous eyestalk in a shark (which he mistook for the optic nerve.) The Dutchman Coiter (1534-1576) first described sclerotic bones in the eye of birds, the Belgian Vesalius (15141564) found the seventh extraocular muscle in the dog and the ox, and the absence of this muscle in humans was noted by the Italian, Eustachius, (in 1552; confirmed by Fallopius,
1561). Fallopius was also the first to discover the three semicircular canals of the inner ear. Fabricius (1533-1619) recorded only six extraocular muscles in man, ape and fishes, compared to seven in most quadrupeds. The detailed discoveries of these and many other early anatomists (see Cole 1949) form the foundations for knowledge of human anatomy expected today of any surgeon.

A new field of comparative embryology, developed mainly after the publication of Darwin's The Origin of Species, revealed other remarkable facts. The segmented muscle blocks evident in the flesh of any fish were found to extend forward into the head region in early shark embryos (Balfour 1878). From these, the development of the standard pattern of vertebrate eye muscles was worked out. Four muscles innervated by the third cranial nerve were derived from the first muscle block, with one muscle developed from the second, and another from the third muscle block, these being innervated by the fourth and sixth cranial nerves respectively.

One hundred fifty years since Darwin, there has been an enormous increase in our knowledge of the comparative anatomy, function and molecular biology of the vertebrate nervous system. For evolutionary biologists, this has provided numerous tests of Darwin's theory. The "camera and lens" type of eye in vertebrates, also developed in the octopus, is one of at least nine design principles amongst the eyes of different animal groups, and much more has been learnt about the diverse structures used for vision across the animal kingdom (Land and Nilsson 2002). The excellent summary presented by Richard Dawkins (1996, pp. 126-179) in Climbing Mount Improbable (Chapter 5 "The Forty-fold Path to Enlightenment") argues that complex eyes may have evolved at least 40 and perhaps up to 60 times independently in different animal groups (but see Gregory 2008). From an initial patch of lightsensitive cells facing in one direction, it is inferred that the elaboration towards true (image-forming) vision would first require an ability to detect the direction from which light was coming. This would be most simply achieved by bending the light-sensitive surface so that the photoreceptor cells receive light from different directions, either inwards to form a cup, or outwards as a convex curve. The first solution would result in the "camera-style" eye such as possessed by modern vertebrates, and the second a "compound eye" such as possessed by modern insects.

By analogy with the lens, film, and light-proof outer casing of a basic camera, the camera eye at its simplest would require three layers of cells with comparable functions: a protective outer layer that was transparent to let light in, a middle layer of light-sensitive cells, and a basal opaque layer to trap the light. In an elegant computermodeling program, involving simulation of minor modifications to improve optical performance starting from this 
basic arrangement, and using very conservative estimates of heritability and population variation, Nilsson and Pelger (1994) showed that to elaborate from a flat light-sensitive patch, through a cup-shaped invagination, to a camera-style eye, complete with graded lens similar to that of a fish, could be achieved in about 364,000 generations. This could have taken place in about 0.5 million years, a minute segment of geological time.

The computer simulation simplified things greatly by considering only one aspect of the complexity of the vertebrate eye. Other major aspects of complexity not taken into account were: (1) the preceding requirement to evolve the initial light-sensitive cells (photoreceptors); (2) the "wiring" of those cells to the control center, i.e. the nervous connections between eye and brain; (3) the mechanisms needed to control eye movement, particularly to fix the gaze on an object whilst the body of the observer is moving; (4) the ability to adjust focus of the lens, either by moving it forwards or backwards (as in fish, amphibians, some reptiles), or by altering its shape (as in some reptiles, and all birds and mammals) and (5) the ability to change the aperture through which light is admitted.

Regarding point 1 , molecular genetics now indicates that an ancestral light-sensitive patch may have developed only once, in a very early common ancestor, at least of all bilateral animals, if not earlier. This is based on the remarkable observation that the same or corresponding genetic control over eye development (the Pax6 gene and its equivalents) has been found in groups as disparate as mammals, insects, molluscs and worms (Gehring 2005). Regarding points 3 and 4, fossil evidence presented below shows that high-complex mechanisms for eye movement and focus were already evolved some 400 mya.

For those who support "Intelligent Design" and/or reject the notion that life has evolved during some 3.5 billion years of Earth history, all the evidence from living species may be dismissed as irrelevant speculation, because it is derived from the present, whereas Darwinian evolution is concerned with evolutionary change operating over many millions of years in the geological past. To answer such claims, some tangible fossil evidence of fundamental evolutionary change from deep within the history of life on this planet is described in the next section.

\section{Fossil Evidence of Eye Structure in Early Vertebrates}

Opponents of Darwinian evolution still rely on the argument of a poor or absent fossil record, but many new discoveries have been made since Darwin's time, and documentation of the history of past life on our planet has greatly improved. For backboned animals (vertebrates,) this includes some very rare but detailed evidence of the early evolution of that most complex organ, the brain, and its sensory organs, including the eye.

The issue of organ complexity in the fossil record can be a double-edged sword. A "good" fossil record would be a series of fossils from different ages documenting an "evolutionary trend" through geological time, the "lineage....of progenitors" wished for by Darwin. On the other hand, just one highly complex fossil, perhaps completely isolated in time by millions of years, can be of great significance because its complexity carries enormous information content. If "structural complexity," which we have learnt about through centuries of scientific research into the comparative anatomy of living organisms, can be presented as an argument against Darwinian evolution, then a structurally complex fossil is equally valid evidence for the other side of the argument.

It is commonly thought that the fossil record of the vertebrate brain is limited to general evidence of size and shape derived from the skull cavity of extinct mammals. To quote Richard Dawkins (The Blind Watchmaker, p. 188): "Brains themselves do not fossilize, but skulls do, and the cavity in which the brain was housed - the braincase-if interpreted with care, can give a good indication of brain size.” Also (Dawkins 1991, p. 40): “Eyes don't fossilise, so we don't know how long our type of eye took to evolve its present complexity and perfection from nothing, but the time available is several hundred million years." Regarding the computer simulation indicating rapid evolution of a camera-style eye, Dawkins (1996, p. 176) noted that such an evolutionary rate would be geologically instantaneous, so finding fossils recording transitional stages would be a matter of extreme luck. In any case, one would not "expect to be able to see the details of eyes in fossils, because they are too soft to fossilize." A well-known exception is the diversity of compound eyes (like those of modern insects) documented in extinct trilobites, because the lenses of tiny calcite crystals are hard, and are often preserved as fossils (for a review see Fortey 2000).

Otherwise, vertebrate fossils can provide a general idea of eye structure from the size of the orbit (eye socket) in preserved skulls, or from the size of the "sclerotic ring," a circle of bones that may develop on the outer surface of the eyeball to help maintain its spherical shape, particularly when it is relatively large (among living groups this structure occurs in various birds, reptiles and fishes.) The sclerotic ring, when preserved in fossils, gives a general idea of overall size of the eyeball, for example in ichthyosaurs, a group of Mesozoic marine reptiles that seem to have had large eyeballs for the low light conditions associated with deep diving (Motani et al. 1999).

However, the type of fossil preservation discussed in this article is largely unmentioned in general textbooks or more 
popular books on evolution. This concerns some surprising detail on the early evolutionary history of the vertebrate central nervous system and major sense organs. Of course, we would not expect the preservation of ancient structures made entirely of soft tissues (e.g. rods and cone cells in the retina; the billions of neurons, nerve tracts and grey and white matter within the brain). Furthermore, vision is a "process," not observable in fossils, in which the function of preserved parts can only be inferred by comparison with presumed equivalents in their living relatives, where functions can be observed.
It is obvious that the best fossil record is provided by groups with a mineralized skeleton; but, in rare instances, soft-bodied organisms can be preserved, for example in the famous Middle Cambrian Burgess Shale fauna of Canada or the more recently discovered Early Cambrian Chengjiang fauna of China (Shu et al. 1999). A variety of forms in the Chengjiang fauna had eyes, and these include two forms, Haikouichthys and Myllokunmingia, interpreted as stem vertebrates (there is disagreement about whether one or more types may be present, the morphological differences alternatively explained as due to different preservation.)

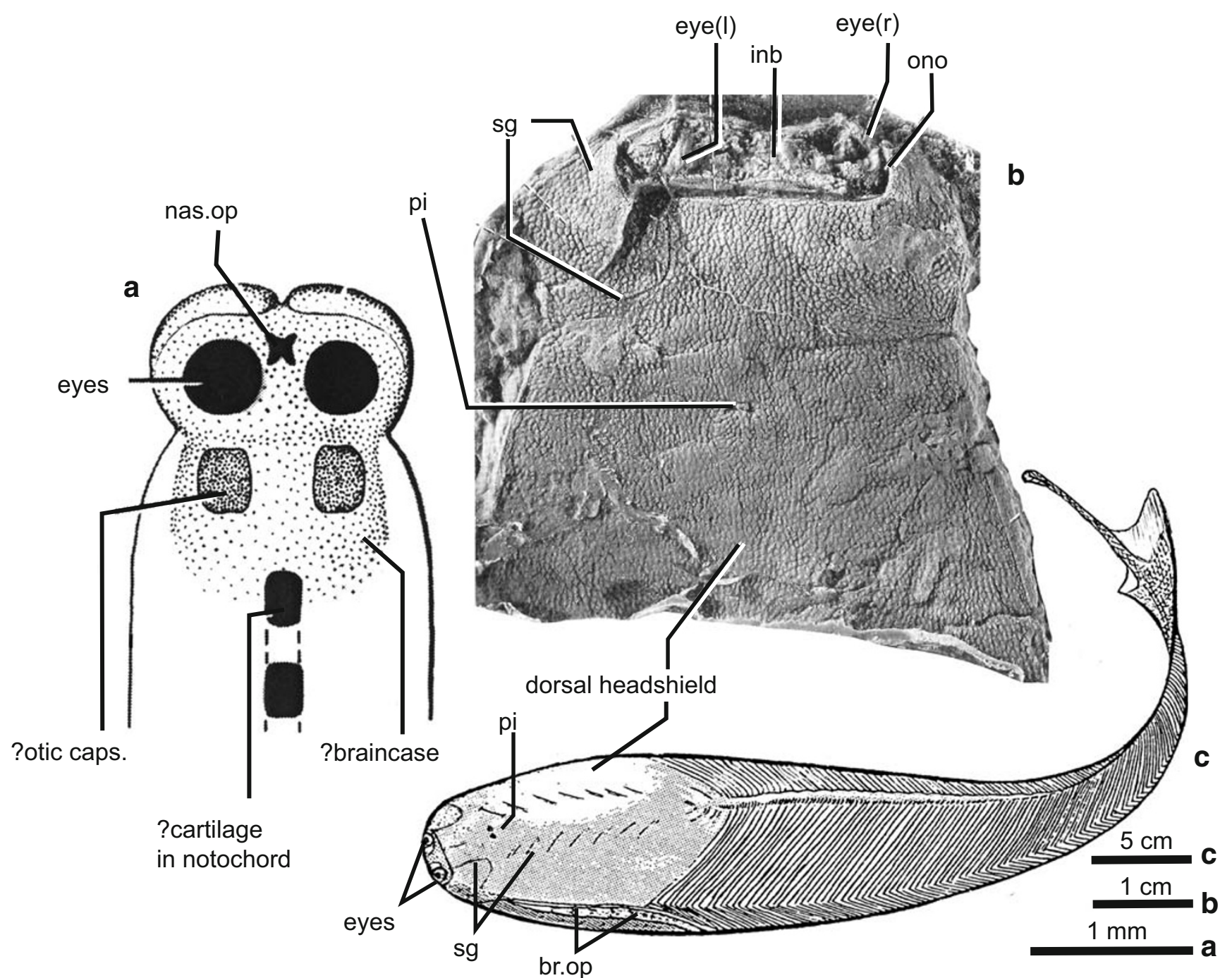

Fig. 1 a Interpretation of the head in dorsal view of the Early Cambrian stem vertebrate Haikouichthys from the Chengjiang fauna of Yunnan Province, China, showing the presumed cartilaginous braincase (stippled) at the anterior end of the notochord. The braincase evidently included the three major sense organs of vertebrates: paired nasal openings (nas.op), paired eyes, and probably an acoustico-lateral line system suggested by paired otic capsules (otic caps.). b Dorsal view of an incomplete headshield of the arandaspid agnathan Sacabambaspis from the Ordovician of Bolivia, showing the unique paired pineal openings ( $p i)$, sensory grooves $(s g)$ of the lateral line system, and an anterior orbitonasal opening (ono). This housed both eye capsules, with the nasal openings separated by an internasal bone (inb). c Sacabambaspis (Ordovician, Bolivia); reconstruction of the whole fish in left dorsolateral view, showing the position of the eyes, paired pineal openings ( $p i)$, sensory groove system $(s g)$, and branchial openings (br.op). a modified from Janvier (2003, Fig. 2c); b, c modified from Gagnier (1995, Figs. 3 and 4) 
The vertebrate affinities of these small elongate animals is indicated by the following preserved features (Janvier 2003): a head, a distinct branchial region with six filamentous gills, chevron-shaped myomeres (muscle blocks) along the body, and possible cartilaginous elements perhaps supporting the branchial apparatus surrounding the anterior part of an axial skeleton (notochord). Shu et al. (2003) reported many new examples of the form called Haikouichthys, including some that are dorsoventrally compressed, showing the structure of the 1-2-mm-sized head from above. Small paired openings near the midline at the front probably connect to the olfactory organs (nas. op, Fig. 1a), behind which are large paired eyes and posterior paired structures (possible otic capsules) surrounded by a smooth area indicating some type of fibrous or cartilaginous braincase (Janvier 2003). Thus, it is probable that these animals already possessed all three senses (olfactory, optic and otic regions of the brain), although more details of the major sense organs are unknown at present.

Following this is a gap in the vertebrate fossil record of some 30 million years, before the first mineralized skeleton developed. Hard tissue (skeletal) fragments assigned to early vertebrates have been found in Late Cambrian strata (e.g. Young et al. 1996), but it is only in the Early-Middle Ordovician that we have good evidence of the early armoured agnathans (jawless vertebrates). At their first appearance, they are represented by two major Ordovician groups: the Arandaspidida from Australia and South America, and the Astraspidida from North America. These are allied to the Heterostraci of the Silurian and Devonian periods, by which time several other major armoured agnathan groups (osteostracans, galeaspids, pituriaspids) are well documented by numerous fossils, revealing a detailed morphology (summarized in Janvier 1996, pp. 85-123).

The appearance of a hard skeleton within the vertebrates was a major evolutionary advance, and to describe some of the stages through which the skeleton evolved, it is necessary first to understand that the apparently unified single system of bones in a living mammal is in fact derived from two separate systems. These were originally quite distinct in early vertebrates. An external or dermal skeleton can only form in the skin (in a mammal exemplified by the bones on the top of the human skull,) while the internal, or endoskeleton, comprises elements first formed as cartilage, that later ossify (e.g. the backbone). Components of both skeletal systems may be preserved as fossils, and it is important to distinguish between them.

The well-developed dermal skeleton enclosing the head of the Ordovician arandaspid Sacabambaspis from Bolivia shows a unique condition of the pineal body or 'third eye' at the top of the brain (pi, Fig. 1b,c) - there are paired (pineal and para-pineal) openings, whereas in other early vertebrates with a pineal opening, it is always a single foramen through
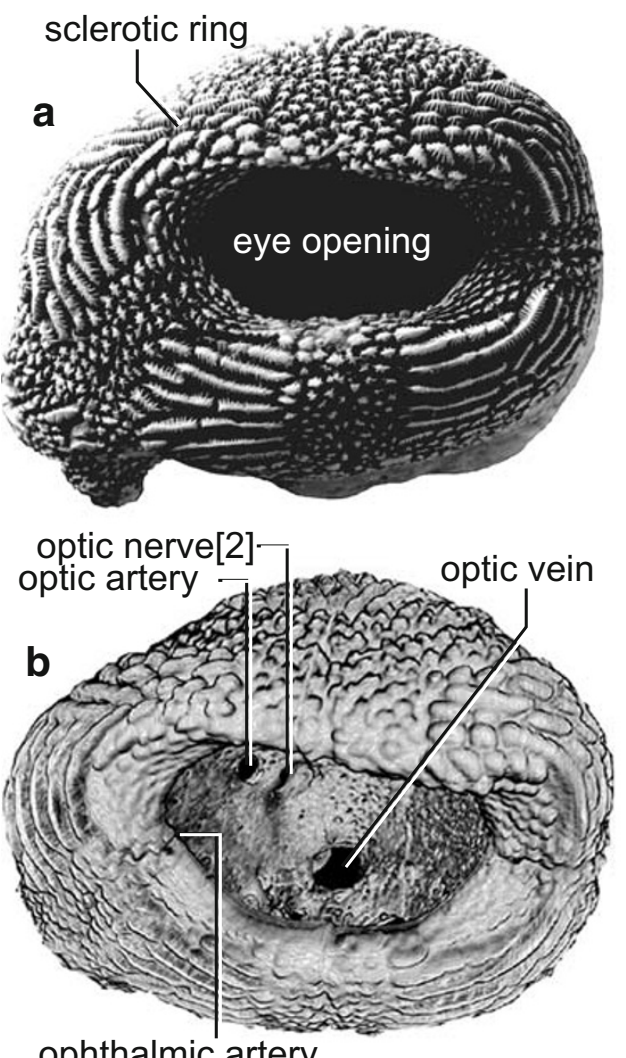

ophthalmic artery

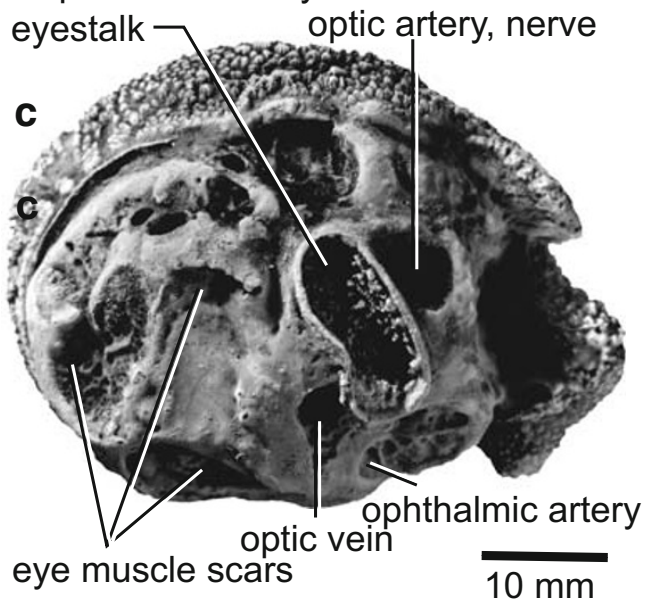

Fig. 2 Perfectly preserved 400-million-year-old left eye capsule of a placoderm fish, acid-etched from Lower Devonian limestones of the Burrinjuck area, New South Wales, Australia (Murrindalaspis, first described by Long and Young 1988). a External view showing the dermal sclerotic ring; b XCT scan revealing the inside of the eye opening, to show structures on the retinal wall (CT scanning and imaging by Prof. T. Senden and Dr A. Limaye, ANU); c internal view of the sclerotic cartilage enclosing the eyeball, showing scars for eye muscle attachment, the eyestalk attachment and openings for the optic nerve, and arteries and veins supplying the eyeball

the top of the skull. Sacabambaspis had small anteriorly placed eyes (Fig. 1c), at least partly enclosed by an endoskeletal capsule, and perhaps with an outer (exoskeletal) "sclerotic ring," also seen in the small lateral eyes of the Ordovician Astraspis from North America. Small lateral eyes 
were also characteristic of the Heterostraci (Early SilurianLate Devonian); these had no internal (endoskeletal) ossification, but impressions suggest a semi-conical eyeball (Janvier 1996, p. 94). Another group (anaspids) had larger lateral eyes surrounded externally by a non-sclerotic dermal cover and possibly an accommodation device (corneal muscle) similar to the living jawless lamprey (Janvier 1996, p. 103).

The heavily armoured Osteostraci are the first group to give detailed evidence of eye morphology, with a true sclerotic ring, and the braincase and internal sclerotic cartilage preserved as perichondral ossifications (discussed further below). The braincase internal structure shows that the inner ear comprised only two semicircular canals, compared to three in all the jawed vertebrates (gnathostomes). The eye sockets (orbits) of osteostracans display distinct muscle depressions called myodomes, which demonstrate the presence of extraocular muscles for moving the eyeball (Janvier 1975).

How can we work out the detailed morphology of cranial nerves, and arteries and veins connected to the brain, in fossil groups that are entirely extinct? Furthermore, how can we interpret fossil evidence to permit a reconstruction of the "soft" tissues of the eyeball, as illustrated in Fig. 2? This unique and exquisitely preserved Australian fossil is a 400million-year-old complete eye capsule from an armoured (placoderm) fish. These were the dominant jawed vertebrate group during the Devonian Period (415-360 mya) and are presumed to be the sister group to all the other jawed vertebrates (Goujet and Young 2004). It was noted above that the vertebrate skeleton comprises two separate and quite distinct systems in early vertebrates. The beautifully sculptured surface surrounding the eye opening in Fig. $2 \mathrm{a}$ is made up of five fused bones of the sclerotic ring, part of the external or dermal skeleton, with the sculptured ornament being the same as on the skull bones of that fish.

The inner or sclerotic coating at the back of the retina in the modern eyeball (equivalent to the "white" of the human eye) may be a cup of cartilage, and is part of the endoskeleton. The "white" of the eye is a fibrous layer in mammals, but the original cartilage cup formed in the embryo as an outgrowth of the cartilaginous braincase. In most modern cartilaginous fishes (sharks and rays), the eyeball is still connected to the braincase by a cartilaginous eyestalk.

Cartilage is soft and flexible compared to bone, and it readily rots away. It is very rarely preserved in fossils and, unlike bone, would not be expected to survive for 400 million years. However, an obscure development in some of the earliest vertebrates possessing a mineralized skeleton, such as the osteostracan agnathans mentioned above, and the jawed placoderm fishes, provides the key to the preservation of cartilaginous structures.

The growing outer surface of any cartilage is a thin layer of dense cells called the "perichondrium." For some reason, in the early placoderms, this was the only part of the internal skeleton that could ossify. The unornamented inner side of the placoderm eye capsule (Fig. 2c) is actually two paper-thin layers of perichondral bone, enclosing a space originally filled with cartilage. It is completely joined to the outer sclerotic ring, such that the preserved structure surrounded or "encapsulated" the eyeball; hence, the term "eye capsule" for this unit, even though it is made up of two components of different origin.

Because it is an enclosing capsule, every nerve or blood vessel entering or leaving the eye is preserved as a distinct openings through both perichondral layers. The unornamented inner half of the eye capsule, which fitted into the orbit (eye socket) of the skull, shows depressions and ridges for attachment of the extraocular muscles (Fig. 2c). Inside the capsule are small processes just inside the eye opening, which presumably helped support the lens of the eye. Such detail is completely preserved and is incontrovertible evidence that most complexities of the vertebrate eye had already evolved by 400 mya. On the other hand, there are also some significant differences from the eyes of living vertebrates, for example in the arrangement of the extraocular muscles that moved the eyeball in its socket, as outlined below. Thus, it cannot be claimed that this complex fossil is no different from the corresponding structure in modern animals and, therefore, shows that evolutionary change has not occurred, another spurious argument used by some "creationists."

To recognise a single eye capsule such as this in isolation, let alone to interpret its complexity in a meaningful way, would be extremely difficult without a wealth of supporting information about the brain of these early vertebrates. Nearly 90 years ago, a Swedish researcher, Erik Stensiö, was the first to notice thin dark lines (the same perichondral bone layers) in the rock matrix inside a fossilized placoderm fish skull. His detailed interpretations of the internal structure of the braincase in this and other early vertebrates (e.g. Stensiö $1925,1927)$ caused some amazement and suspicion that it could not be possible to extract such information from fossils that old (see Janvier 1996, p. 315).

Stensiö later applied the technique of serial grinding to great effect, even if the fossil (and any chance of checking interpretations) was destroyed in the process. Successive layers were ground away until nothing was left, but crosssectional drawings or photographs were prepared at each stage and used to reconstruct brain structure in threedimensional wax models as a basis for comparisons of brain structure in a range of early vertebrate groups (see Stensiö 1963). Detailed mechanical preparation of similar material (e.g. Goujet 1984; Janvier 1985) substantiated many of Stensiö's interpretations, but some significant points required amendment.

About 60 years ago, a major advance in techniques of fossil extraction exploited the different chemical reaction of bone 


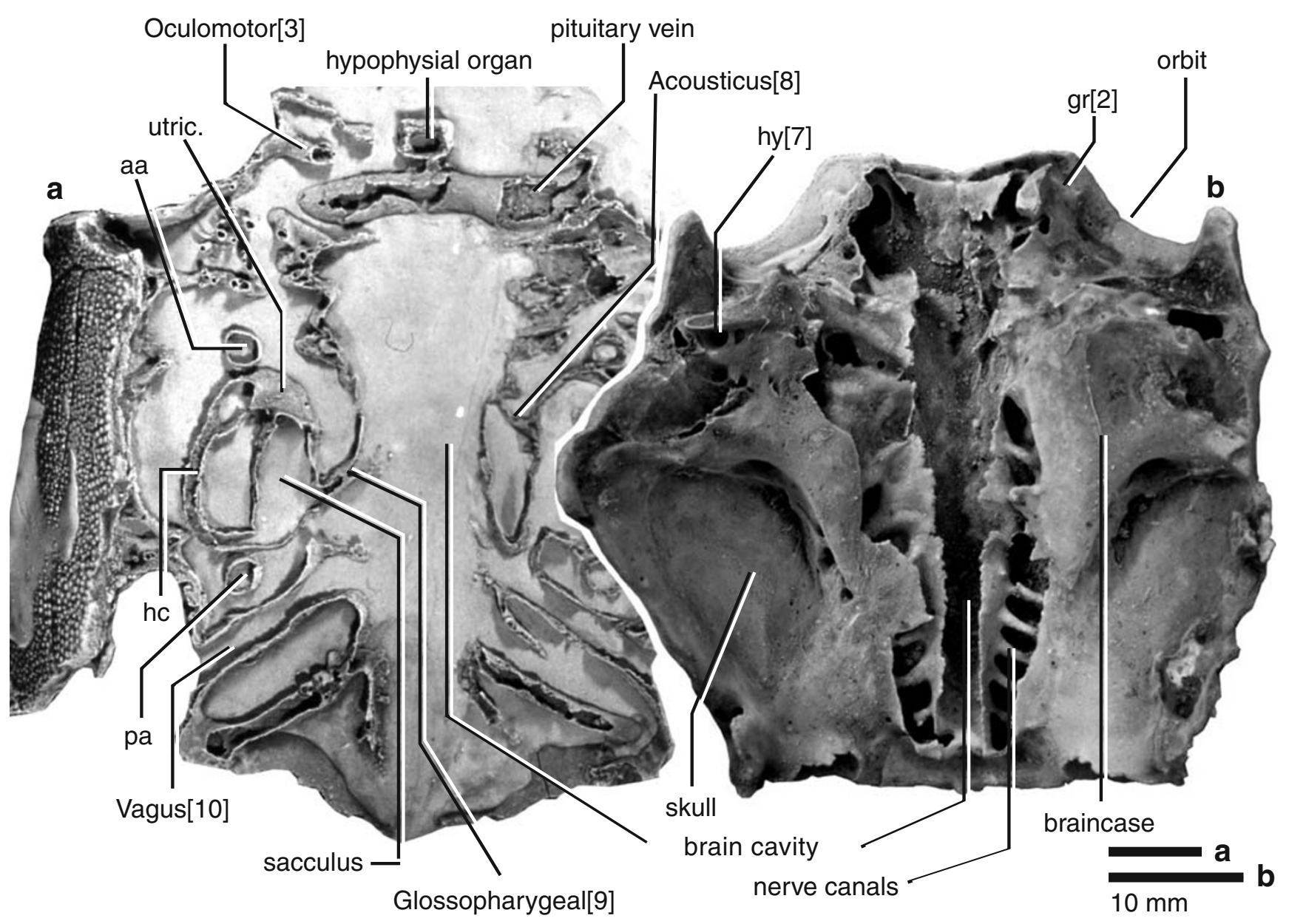

Fig. 3 Two skulls of arthrodire placoderms from the Lower Devonian limestones of the Burrinjuck area, New South Wales, Australia. a Skull roof bones have been eroded off from above, to reveal the internal cavities and nerve canals of the braincase, defined by thin layers of perichondral bone (Buchanosteus, first described by Young 1979). b Smaller skull from below, with braincase still attached to dermal skull roof (extracted from limestone with acetic acid). The floor of the braincase and of the central brain cavity are broken. Cranial nerves labelled and/or numbered are the oculomotor nerve (3), acousticus nerve (8), glossopharyngeal nerve (9) and vagus nerve (10). The optic nerve (2) is represented by a groove at the front of the braincase (gr [2]); the hyomandibular branch of the facial nerve (7) is indicated by a large opening (hy[7]). Abbreviations for structures of the inner ear are: aa, ampulla of anterior semicircular canal; hc, horizontal semicircular canal; pa, ampulla of posterior semicircular canal; utric., utriculus (calcium phosphate) embedded in limestone rock (calcium carbonate) when immersed in acetic acid. Acid extraction was perfected in the 1940s in London using Australian fossil specimens from the same area as the material illustrated here. As the acid etched away the rock, the British researchers were amazed to see structures of the braincase emerging in the form of thin perichondral bone layers. The first scientific research based on this new fossil preparation technique was published by White (1952). The technique is now used in palaeontological laboratories throughout the world, to extract vertebrate bone from calcareous rocks.

Specimens partly eroded by weathering when found (e.g. Fig. 3a) can be acid-etched to reveal the internal braincase cavities and canals for cranial nerves and blood vessels, all of which were lined with perichondral bone. Most recently, the internal structures have been investigated using X-ray computed tomography (XCT) scanning techniques (Fig. 2b). The placoderm brain cavity is a long central tube, from which smaller tubes emanate (Fig. 3b). The walls of the braincase were much thicker than the central brain cavity, so the detailed course of the nerves, arteries, and veins passing to and from the brain can be worked out in great detail. The labyrinth cavity of the inner ear is entirely embedded in the thick braincase wall, so its three semicircular canals with their ampullae, and the sacculus and utriculus, are completely preserved (Fig. 3a). Each semicircular canal is oriented at 90 degrees to the other two, as an organ of balance to determine position in threedimensional space. The Burrinjuck fossil fish demonstrate that the basic inner ear structure of jawed vertebrates was fully evolved by 400 mya. In contrast, all jawless vertebrates, both living and extinct, lack the horizontal 


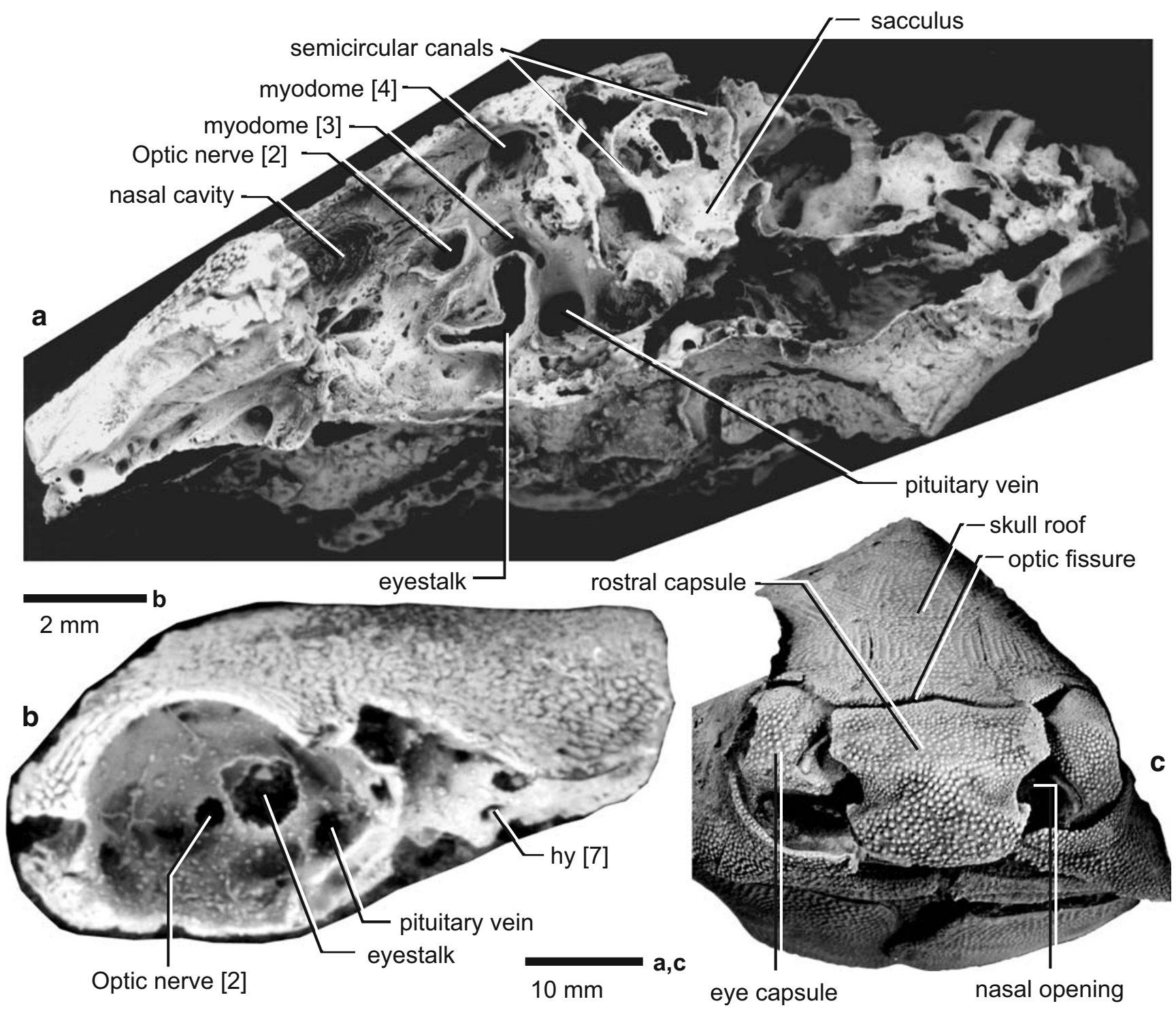

Fig. 4 a Left side of an eroded braincase of the placoderm fish Brindabellaspis Young, 1980 from Wee Jasper, Burrinjuck area, New South Wales, Australia. The specimen has been acid-etched from limestone to reveal preserved braincase structure in the form of perichondral bone layers (specimen illustrated by Goujet and Young 2004). Muscle pockets in the orbit (myodomes) are numbered according to the cranial nerve canals that connected them to the brain cavity (third and fourth cranial nerves). b Left lateral view of the

semicircular canal, suggesting that this structure "coevolved" when jaws first appeared.

The labyrinth cavity is a complex morphological "landmark," by which the various canals for cranial nerves can be identified, according to the numbering system of classical anatomy (from the front backwards). Thus, the eighth cranial nerve (acousticus) enters the labyrinth cavity, the ninth and tenth nerves (glossopharyngeus, vagus) pass under or behind it, and nerves 5-7 (trigeminus, abducens, facialis) emanate in front of the labyrinth and behind the orbit. A major (hyomandibular) branch of the seventh oldest acid-etched braincase of a true bony fish (osteichthyan), also from Wee Jasper, Burrinjuck area (described by Basden and Young 2001); hy [7] is the opening for the hyomandibular branch of the facial nerve (7). c Front view of another arthrodire (the same group as in Fig. 3). This unique specimen shows the complete skull, braincase, cheek, and jawbones, with both eye capsules and the rostral capsule in place (jaws described by Young et al. 2001)

nerve has a conspicuous opening (hy[7], Figs. $3 b$ and $4 b$ ) adjacent to the attachment point for a large gill arch element articulating with the braincase to support the jaws of early gnathostomes. In land vertebrates, this element (the hyomandibula) loses its supporting function to transmit sound into the braincase, ultimately becoming the stapes of the middle ear in mammals.

The orbit is a second major morphological landmark. Nerves 2-4 (optic, oculomotor and trochlear) enter the orbit, and nerve 1 (olfactory nerve) passes forward into the nasal capsules. The openings within the eye socket (e.g. for 
the optic nerve, the largest of the cranial nerves; Fig. 4a,b) closely match those on the back of the eye capsule (Fig. 2c). The vertebrate eyeball is movable inside the orbit, its precise position controlled by six tiny extraocular muscles, with a consistent innervation and developmental pattern determined by comparative embryology of the segmented muscle blocks in the head region of early shark embryos, as mentioned above. The extraocular muscles must form antagonistic muscle pairs (one pulling forward and another backward in each of three dimensions; muscles cannot push). Thus, the basic number of extraocular muscles is six for jawed vertebrates; that is, twice the number of semicircular canals in the inner ear. Attachment scars for these muscles are seen on the inner side of the eye capsule (Fig. 2c), and they originate on the braincase within the eye socket, in specific muscle pockets called myodomes (Fig. 4a), each connected by a short nerve canal to the brain cavity. The relative position of these nerve canals enables their contained cranial nerves to be determined.

The detailed interpretation of this ancient eye muscle pattern and innervation draws heavily on classical anatomy and embryology of living species. The general pattern for all gnathostome (jawed) fishes comprises four rectus muscles attached to the posterior wall of the orbit and inserting around the rim of the eyeball, and two opposing oblique muscles (superior and inferior) that extend back from the anterior orbital wall to insert dorsally and ventrally on the rim of the eyeball (Young 2008). The consistent position and innervation (one muscle each innervated by cranial nerves 4 and 6 , the remaining four innervated by the oculomotor nerve 3 ) indicates that this is a highly conserved and presumably ancient system among the vertebrates. As stated by Neal (1918, p. 433), the extraocular muscles "appear in the lower vertebrates in essentially the same form as in man. Indeed, their number and their nerve relations are the same in man as in the dogfish...only the superior oblique shows a function change in the course of phylogeny." The "function change" refers to the living lamprey, in which the muscle corresponding to the gnathostome "superior oblique" (based on the same innervation by cranial nerve 4, the trochlearis) has a posterior rather than anterior attachment and insertion on the eyeball.

Remarkably, the 400-million-year-old extinct placoderm fish from Burrinjuck shows the same posterior attachment for the superior oblique eye muscle as in the modern agnathan, the lamprey (Young 1986). Together with the presence of jaws in placoderms, this represents a unique character combination, unknown in any other jawed vertebrate-all other vertebrates with jaws, both living and extinct, have the corresponding muscle attached on the front of the orbit. In addition, the placoderm eyeball was supported by a strong cartilaginous eyestalk (Fig. 4a), as in modern sharks. The eyestalk attachment now seems to represent the ancestral condition for all jawed vertebrates because it has recently been identified as well in a true bony fish specimen from Burrinjuck (Fig. 4b), representing the oldest acid-extracted osteichthyan braincase (Basden et al. 2000). The everted rim of the largest opening in the orbital wall, also evident in the placoderm braincase (eyestalk, Fig. 4a,b), demonstrates that this was cartilage-filled, and could not have contained a nerve or vessel. The smaller round opening in front has inturned margins continuing into the central brain cavity as a nerve canal; this is the canal for cranial nerve 2, the optic nerve (Fig. 4b). In modern teleosts (ray-finned fish), the most diverse living vertebrate group, and the living descendants of this ancient osteichthyan, the cartilage connection between eyeball and braincase has been lost, but the unique specimen of Fig. $4 \mathrm{~b}$ indicates that the connection must have been a primitive feature, at least for all jawed vertebrates.

Another unique condition of placoderm fishes is a subdivision of the braincase into two separate ossifications at the level of the optic nerve. Thus, the anterior part of the braincase (rostral capsule, Fig. 4c) generally falls away, leaving half of the optic nerve canal as a deep groove at the front of the posterior part (gr[2], Fig. 3b). Interpretation of this groove as having contained the optic nerve has been confirmed by a single complex fossil, a complete skull and braincase with both eye capsules and the rostral capsule in place, showing this "optic fissure" as a transverse slit passing right across the skull between the eye sockets (Fig. 4c).

\section{Conclusions}

Presented here is a very brief summary of some of the evidence of detailed brain morphology that can be retrieved from the fossil record of early vertebrates. Such complexity, revealed by 400 -million-year-old fossils, would not have been imagined possible by Charles Darwin in 1859. However, all the observations are entirely consistent with predictions of his theory, as well as the computer modeling predictions indicating evolution of an eye by small increments in less than one million years. Rather than "intelligent design," the structure of the oldest preserved fossil evidence for the vertebrate eye and brain shows the legacy of an ancestral segmented animal in the derivation and arrangement of nerves and muscles controlling eye movement, subdivision of the braincase, and other features. Despite the complexity, the organisation of the brain and eye in the 400-million-yearold fossil fish from Burrinjuck illustrated here demonstrate a unique morphology, intermediate between living jawless and jawed vertebrates. Thus, they fit neatly within both a morphological "gap", and a significant hiatus in the fossil record. Like the osteichthyan braincase from Burrinjuck, 
and many other vertebrate fossils elucidated since Darwin's time, these are examples of the transitional forms that he predicted - they show combinations of characters that have never been observed together in living species.

Finally, this brief essay attempts to convey some sense of the historical development of science-advancements in knowledge since the work of Charles Darwin who, in turn, was accommodating a vast body of previous evidence accumulated by dedicated scientists over at least 2,000 years of detailed human enquiry into the complexity of life on earth. It is appropriate, therefore, to finish by expanding slightly the quotation from The Origin of Species given in the first paragraph of the Introduction. Darwin stated (1859, p. 133): 'To suppose that the eye...could have been formed by natural selection, seems... absurd in the highest degree. When it was first said that the sun stood still and the world turned around, the common sense of mankind declared the doctrine false'.

Acknowledgments I thank T. Ryan Gregory for the invitation to contribute this article and for editorial support, two anonymous reviewers for helpful comments, Tim Senden and Ajay Limaye (ANU) for scanning images (Fig. 2b), and Philippe Janvier and Pierre-Yves Gagnier (Paris) for permission to use and modify their reconstructions (Fig. 1). Supporting research is funded by an Australian Research Council Discovery Project (DP0772138: "Old brains, new data").

\section{Glossary of terms}

Acousticus (cranial nerve)

the eighth cranial nerve (also called 'vestibulocochlear'), which innervates the inner ear

Abducens (cranial nerve)

agnathans

ampulla (ampullae)

anatomy

(comparative)

braincase

the sixth cranial nerve, a motor nerve innervating one or two of the extraocular muscles controlling eye movement vertebrates that lack jaws, of which there are two modern types (lampreys and hagfish); fossil representatives, with a well-ossified skeleton, are much more diverse (e.g. Arandaspidida and Astraspidida from the Ordovician, Heterostraci, Osteostraci, Galeaspidida, Pituriaspidida from the Siluro-Devonian)

an expansion in each semicircular canal which housed hair cells that respond to liquid movement within the inner ear cavity the structure of the body, strictly speaking as worked out from the method of dissection (from the Greek anatome; to cut up or dissect); comparative anatomy compares structures in different animals to elucidate their evolutionary origins. The term applies to fossil investigation particularly when "dissecting" techniques are used to extract information (e.g. acid etching, serial sectioning, etc.).

a block of cartilage, part of the endoskeleton, formed as an expansion of the anterior end of the vertebral column, to house the brain; in placoderms and osteichthyans, it is enclosed by skull bones of the dermal skeleton. In a mammal, the ossified braincase and the dermal skull bones are intimately connected one of two major groups of living fishes (the cartilaginous fishes), exemplified by modern sharks and rays, with an internal skeleton mainly of cartilage and the external skeleton (except the teeth) mainly developed as tiny denticles embedded in the skin

cranial nerves the major nerves extending out from the brain; 12 pairs numbered sequentially from the front is the traditional scheme based on the condition in mammals; in early fishes some of these are not developed, or composite origin is indicated by separate nerves

dermal skeleton

the external skeleton of vertebrates formed in the skin (dermis) and comprising various types of hard bony tissues (including dentine and enamel) but never cartilage; examples in a mammal are the bones at the top of the skull, the teeth and the clavicle bone in the shoulder girdle

embryology (comparative) the study of embryos at different stages to investigate the development of different organs and structures and to compare development in different animals to elucidate the evolutionary origin of shared features

endoskeleton the internal skeleton of vertebrates always forming first as cartilage, which may later be partly or completely replaced by bone. Examples are the braincase and vertebral column and the limb bones of mammals. see dermal skeleton

exoskeleton extraocular muscles the muscles controlling movement of the eyeball, the basic arrangement being four rectus muscles spreading out from the back of the eye socket to insert around the rim of the eyeball and two oblique muscles extending out from the anterior part of the eye socket to insert at the top and bottom of the eyeball rim

eyestalk a flexible rod of cartilage (also called the "optic pedicel") that connects the eyeball to the braincase in most modern cartilaginous fishes (sharks and rays)

Facialis (cranial nerve) the seventh cranial nerve, partly sensory (with fibers to the taste buds) but mainly a motor nerve controlling the muscles of the face in mammals (hence, its name) and also the stapedial muscle (all derived from the branchial muscles of the hyoid arch in a fish)
Glossopharyngeus (cranial nerve)

hyomandibula gnathostome the ninth cranial nerve, supplying the first branchial arch in fishes; in mammals innervating the throat and tongue a vertebrate possessing jaws, apparently formed originally by enlargement and strengthening of the front pair of gill arches (the mandibular arch), on which were developed various biting structures like teeth and jawbones the upper element of the first gill arch behind the jaws (the hyoid arch), in most gnathostome fishes enlarged to support the 
jaws but losing this function in land animals (ultimately becoming the mammalian stapes in the middle ear)

labyrinth cavity

myodome

oculomotor nerve (cranial nerve)

olfactory capsule

olfactory nerve (cranial nerve)

optic nerve

(cranial nerve)

orbit

ossify

osteichthyans

otic capsule

perichondral

(layer or bone)

placoderms the cavity of the inner ear; in mammals, enclosed in intricate spaces within the periotic bone, suggesting the maze of winding passages without exit from Greek mythology (from which the name is derived); it contains the organ of balance, the liquidfilled "membranous labyrinth,"

a pocket within the eye socket containing the attachment for one or more extraocular muscles; most teleost fishes have a very large posterior myodome for the four rectus muscles the third cranial nerve, a motor nerve innervating four of the gnathostome extraocular muscles controlling eye movement

the paired cartilaginous capsule at the front of the braincase enclosing the nasal sacs

the first cranial nerve, the sensory nerve for olfaction (sense of smell), unusual in having the cell bodies in the epithelial lining of the nasal sacs, with sensory fibers running back to the olfactory bulb of the brain the second cranial nerve, more properly considered a tract of the brain because the cell bodies of optic nerve fibers are in the retina, and this forms embryologically as an outgrowth of the brain tube

the socket on each side of a skull that contains the eyeball

to turn into bone; i.e. the process involving deposition of mineralized hard tissue in the form of calcium phosphate, secreted by specialised bone-forming cells (osteocytes) the second major group of living fishes, differing from sharks and rays (see chondrichthyans) in possessing a complete bony skeleton. Two major subdivisions are the ray-finned fishes (Actinopterygii, the dominant modern group) and lobe-finned by a few species of lungfish, and the coelacanth Latimeria)

a paired cartilaginous part of the braincase located behind the eyes, and enclosing the labyrinth cavity, containing the organ of balance in early aquatic vertebrates a connective tissue layer of dense cells on the growing surface of a cartilage, which may ossify as concentric layers of bone (termed "periosteal" bone when the inner part of a cartilage is also replaced by bone)

the extinct armoured fishes, the most diverse jawed vertebrates during the Devonian Period. An external skeleton of bony plates enclosed the head and shoulder girdle but with a different pattern to the osteichthyan fishes, suggesting that part or all of the dermal skeleton evolved independently. Some placoderms had blade-like cutting toothplates in the jaws, but they lacked true teeth fishes (Sarcopterygii; represented today only sacculus

semicircular canal

trigeminus (cranial nerve)

trochlear nerve (cranial nerve)

utriculus

vagus

(cranial nerve)

\section{References}

Balfour FM. A monograph on the development of elasmobranch fishes. London: Macmillan; 1878.

Basden AM, Young GC. A primitive actinopterygian neurocranium from the Early Devonian of southeastern Australia. J Vertebr Paleontology. 2001;21:754-66. doi:10.1671/0272-4634(2001) 021[0754:APANFT]2.0.CO;2.

Basden AM, Young GC, Coates MI, Ritchie A. The most primitive osteichthyan braincase? Nature. 2000;403:185-8. doi:10.1038/ 35003183 .

Cole FJ. A history of comparative anatomy from Aristotle to the eighteenth century. London: Macmillan; 1949. (1975 edition, New York: Dover).

Darwin C. The origin of species by means of natural selection (6th edition). New York: The Modern Library, Random House; 1859.

Dawkins R. The blind watchmaker. London: Penguin; 1991. p. 340.

Dawkins R. Climbing mount improbable. New York: Viking; 1996. p. 308.

Fortey R. Trilobite! Eyewitness to evolution. London: HarperCollins; 2000. 284 pp, Random House, New York.

Gagnier P-Y. Ordovician vertebrates and agnathan phylogeny. Bull Mus Natl Hist Nat Paris. 1995;17:1-37. 
Gehring WJ. New perspectives on eye development and the evolution of eyes and photoreceptors. J Hered. 2005;96:171-84. doi:10.1093/jhered/esi027.

Goujet D. Les poissons placodermes du Spitsberg. Cahiers de Paléontologie, Section Vertébrés. Paris: CNRS; 1984.

Goujet D, Young GC. Placoderm anatomy and phylogeny: new insights. In Arratia G, Wilson M, Cloutier R, editors. Recent advances in the origin and early radiation of vertebrates. Munich: Verlag Dr. Friedrich Pfeil; 2004. pp. 109-126.

Gregory TR. The evolution of complex organs. Evol Educ Outreach. 2008;1(4). doi:10.1007/s12052-008-0076-1.

Janvier P. Les yeux des cyclostomes fossils et le probleme de l'origine des myxinoides. Acta Zool. 1975;56:1-9.

Janvier P. Les Cephalaspides du Spitsberg. Anatomie, phylogenie et systematique des Osteostraces Siluro-Devoniens. Cahiers de Paléontologie, Section Vertébrés, Paris: CNRS; 1985.

Janvier P. Early vertebrates. Oxford: Clarendon; 1996. 393 pp.

Janvier P. Vertebrate characters and the Cambrian vertebrates. C R Palevol. 2003;2:523-31. doi:10.1016/j.crpv.2003.09.002.

Land MF, Nilsson DE. Animal eyes. Oxford: Oxford University Press; 2002.

Long JA, Young GC. Acanthothoracid remains from the early Devonian of New South Wales, including a complete sclerotic capsule and pelvic girdle. Ass Australas Palaeontol Mem. $1988 ; 7: 65-80$

Motani R, Rothschild BM, Wahl W. Large eyeballs in diving ichthyosaurs. Nature. 1999;402:747. doi:10.1038/45435.

Neal HV. The history of the eye muscles. J Morphol. 1918;30:433-53. doi:10.1002/jmor.1050300202.

Nilsson DE, Pelger S. A pessimistic estimate of the time required for an eye to develop. Proc R Soc Lond. 1994;256:53-8. doi:10.1098/rspb.1994.0048.

Paley W. (1802) Natural Theology; or, Evidences of the Existence and Attributes of the Deity, collected from the Appearances of Nature. 5th edition, printed for R. Faulder, 1803.
Stensiö EA. On the head of the macropetalichthyids, with certain remarks on the head of the other arthrodires. Publ Field Museum Nat Hist Geol. 1925;4:87-197.

Stensiö EA. The Devonian and Downtonian vertebrates of Spitsbergen. 1. Family Cephalaspidae. Skrifter Svalbard Ishavet. 1927;12:1-391.

Stensiö EA. The brain and cranial nerves in fossil, lower craniate vertebrates. Skrifter u. Norsk. Videnskaps Akad. Oslo Mater Naturo K1. 1963;13:1-120.

Shu DG, Luo HL, Conway Morris S, Zhang XL, Hu SX, Chen L, et al. Lower Cambrian vertebrates from south China. Nature. 1999;402:42-6. doi:10.1038/46965.

Shu DG, Conway Morris S, Han J, Zhang ZF, Yasui K, Janvier P, et al. Head and backbone of the Early Cambrian vertebrate Haikouichthys. Nature. 2003;421:526-9. doi:10.1038/nature01264.

White EI. Australian arthrodires. Bull Br Mus (Nat. History) (Geology) 1952;1:249-304.

Young GC. New information on the structure and relationships of Buchanosteus (Placodermi, Euarthrodira) from the Early Devonian of New South Wales. Zool J Linn Soc. 1979;66:309-52. doi:10.1111/j.1096-3642.1979.tb01912.x.

Young GC. A new Early Devonian placoderm from New South Wales, Australia, with a discussion of placoderm phylogeny. Palaeontographica. 1980;167A:10-76.

Young GC. The relationships of placoderm fishes. Zool J Linn Soc. 1986;88:1-57. doi:10.1111/j.1096-3642.1986.tb00876.x.

Young GC. Number and arrangement of extraocular muscles in primitive gnathostomes: evidence from extinct placoderm fishes. Biol Lett. 2008;4:110-4. doi:10.1098/rsbl.2007.0545.

Young GC, Karatajute-Talimaa V, Smith MM. A possible Late Cambrian vertebrate from Australia. Nature. 1996;383:810-2. doi: $10.1038 / 383810 \mathrm{a} 0$.

Young GC, Lelievre H, Goujet D. Primitive jaw structure in an articulated brachythoracid arthrodire (placoderm fish; Early Devonian) from southeastern Australia. J Vert Paleontol. 2001; 18:261-74. 